\title{
Potential Contradictions Connected to the Inclusion of Stable Schools in the Legislation for Danish Organic Dairy Farms
}

\author{
Vaarst, $\mathrm{M}^{1, *}$ and Fisker $\mathrm{I}^{2}$ \\ ${ }^{1}$ Institute of Animal Science, Aarhus Univesity, P.O.Box 50, DK-8830 Tjele, Denmark \\ ${ }^{2}$ Organic Denmark, Silkeborgvej 260, DK-8220 Aabyhøj, Denmark
}

\begin{abstract}
This article aims to raise questions and discuss how a previous farmer-driven group approach (Stable Schools) works under a legislation framework as a part of an obligatory health advisory service for Danish organic dairy producers. The study takes its starting point in an on-line questionnaire evaluation (79 farmer respondents) conducted after one year (2011) with the Stable School approach as part of the legislation. This is followed by a discussion on the perspectives of 'obligatory farmer groups' supported by literature on experience from other institutionalized advisory approaches.

Respondents generally found the Stable Schools useful for many organic farmers, also after introduction to the legislation, given that farmers are motivated and the process is actively supported by a skilled facilitator. We raise the question of a potential mismatch between the legislative aims and the farmer group approach. Shifts between different advisory approaches at the farm level can potentially stimulate continuous on-farm development.
\end{abstract}

Keywords: Farmer learning, stable schools, obligatory animal health advisory service, organic livestock

\section{INTRODUCTION}

Farmer Field Schools (FFS) is a concept for farmers' learning, knowledge exchange and empowerment that has been developed and used mostly in Asia and Africa in many different forms and with different purposes [1]. In an FFS, a group of farmers typically meet regularly to learn together in and from practice, typically on a demonstration farm or plot, and typically with a focus on one enterprise, e.g. rice, cocoa or maize. Minjauw and co-authors [2] described the concept for livestock farms in Kenya, and the first author of this article participated in two Ugandan research projects, where the FFS concept was applied in dairy herds for mastitis reduction [3, 4], and control of tick-borne diseases [5]. In Denmark, an action research project, partly inspired by the Ugandan Farmer Field Schools, aimed at organic farmers' implementation of explicit non-antibiotic strategies though animal health promotion [6]. This approach was a farmerdriven action research project with the focus on phasing out antibiotics $[7,8]$. The only appropriate and sustainable way of reducing or eliminating the use of antibiotics and other medical treatments in a given herd is to eliminate the need for treatments through long-term health promotion and disease prevention initiatives, which is a complex task. One relevant way of reaching this goal was to form participatory farmer groups in an FFS approach, which were adapted to Danish conditions, focused on health promotion, and named 'Stable Schools'. In 2004-2005, four Stable Schools were

*Address correspondence to this author at the Institute of Animal Science, Aarhus Univesity, P.O.Box 50, DK-8830 Tjele, Denmark;

Tel: +45 22901344 Fax +45 899915 25; E-mail: Mette.Vaarst@agrsci.dk established and went through a one-year cycle with monthly visits [6]. Through group focus interviews and individual semi-structured qualitative interviews with all participants, the Stable School approach appeared to stimulate farmers to initiate many new improvements in their herds [6]. Antibiotic use was reduced by $50 \%$ during the project period, without negative side effects regarding animal health and welfare, and this reduced usage was still being maintained four years later [9]. The good results were explained by farmers taking ownership and responsibility over the development in their herds [6]. In a European project, ANIPLAN, a team of researchers focused on animal health and welfare planning as an active process guided and owned by the farmer in interaction with 'external advisors' (including colleague farmers), rather than a production of 'a plan' $[10,11]$. They described a potentially successful planning process with a number of characteristics $[10,11]$, of which the first (1) is that a health planning process should aim at continuous development and improvement, and should incorporate health promotion and disease handling. A continuous process should ensure that current status and risks are regularly assessed. This assessment should provide a justified background for action. Furthermore, a health plan must be 2) farm specific, 3) based on farmer ownership, 4) involve external person(s) and 5) external knowledge, 6) based on organic principles framework and systems approach, 7) be written, 8) acknowledge good aspects of the herd and the farm, and finally 9) involve all relevant persons. Many of these principles apply for a wellfunctioning Stable School: the farmer, the herd, the situation and the farm are the focus, and changes will happen only when those, who should take responsibility for implementing them find such action relevant and necessary. The approach is based on the ideas and theories of experiential learning [11], 
and situated learning [12], in which knowledge is coconstructed in a social process. The learner must guide the process of learning, and base it on active exploration and experimentation in daily practice. In a group of learners, the meaning of the world will be negotiated and re-negotiated in this learning process, given that openness and willingness are shared, to expose one's own experiences, perceptions and life world to the co-learners.

From $1^{\text {st }}$ July 2010, a new obligatory health advisory service was introduced in the Danish Legislation, Directive 786 (https://www.retsinformation.dk/Forms/R0710.aspx?i$\mathrm{d}=132648$ ). According to this, all dairy farmers with herds with more than 100 cows must have an animal health advisory service agreement with animal health professionals. In conventional farming, this was closely linked up to permitting farmers to conduct first-time medical treatments. The veterinarian visits the farm 12-26 times a year and follows a specific plan including clinical examinations of cows at drying off and around calving. This was the first time in Denmark where dairy producers could first-time-treat cows. Organic farmers are not permitted to treat cows with antibiotics or other allopathic veterinary medicine, and therefore can choose other approaches with fewer veterinary inspections under the condition that no severe animal health and welfare problems are identified. The aim of having an animal health advisory service in organic farms is basically to ensure that organic farmers comply with the legislation on animal health and welfare. One option is to participate in a Stable School group and have a veterinary inspection once a year. The other option comprises two annual visits involving both the veterinarian and a cattle production advisor (a livestock advisor with an animal science or technology background, and focus on dairy cow production and health). The latter solution would normally be more expensive than participating in the Stable School. On the other hand, the Stable School will require more working hours to prepare and participate in.

This article aims to raise relevant questions and discuss the potentials of a farmer-driven group approach (Stable Schools) which has been institutionalised from 2011 as part of the legislation framework: 'obligatory health advisory service' for Danish organic dairy producers. It takes its starting point in a questionnaire survey which evaluates the first year (2011) of using Stable Schools as an integrated part of the Danish obligatory health advisory service.

\section{MATERIAL AND METHODS}

\section{The Setting: Danish Organic Dairy Farming}

In 2010 Denmark was the most intensively cultivated European country (63\% of the total land area), with $81 \%$ of the Danish farming area used for fodder production for livestock. In 1985, 2000 and 2010 the number of farms with dairy cows was respectively $31,800,9,800$ and 4,200, with average herd sizes of approx. 28, 70 and 127 cows per herd [13-15]. In 2010, about 62,000 Danish cows were organically certified, distributed between 489 herds (average size approx. 127 cows), with an approximate average milk yield of $8000 \mathrm{~kg}$ per lactation (approximately $1000 \mathrm{~kg}$ below conventional farming). In 2008, only $34 \%$ of herds with more than 100 cows had their cows on pasture, and around $87 \%$ of dairy herds with 100 cows or more had cubicle housing systems. In organic farming, it is a requirement that cows have access to grazing from $15^{\text {th }}$ April to $1^{\text {st }}$ November daily at least 6 hrs with day light. Farmers are generally under much pressure, not only to manage the animals and crops, but also to find their way in a jungle of subsidies, regulations, recordkeeping and forms to fill out, and this becomes an increasing burden for many farmers [16]. In general, Danish organic dairy farmers who are still in business can be assumed to be skilled farmers and farm managers, both because the requirements of an agricultural education today are high, and because they have managed to maintain their farms despite large structural changes, as explained above. Farmers own shares in the dairy company where they deliver their milk, and normally negotiate and set prices for a 5-year period. About a third of all consumed milk in Denmark is organic (approx. 9\% of total produced milk).

\section{The 'Stable School Approach'}

The Stable School concept was developed in 2004-2005, when a group of active organic dairy farmers from the private organic dairy company 'Thise' took the initiative together with the Danish organisation of organic farmers 'Organic Denmark', and the former Danish Institute of Agricultural Sciences to establish a project with the aim of phasing out the use of antimicrobial drugs ('antibiotics') from organic dairy herds, by eliminating the need for treatment through minimising the disease level in the herds. The main approach was to design individual farm and herd strategies through a participatory process using farmer groups for mutual advice, and building up knowledge together which was relevant for the participants. In practice, groups were formed of farmers from 5-8 farms involved in each Stable School Group (one or more participants per farm), who met monthly. The host farmer formed an agenda with two problem areas and one success case and the facilitator guided a process where all farmers gave suggestions in a systematic way. The host farmer(s) concluded and committed him- or herself to certain changes and/or further investigations in possibilities for improvements [8]. This was a very new and unique approach, which is significantly different from the Danish traditional 'experience exchange groups' for farmers, as well as from study groups.

The details of how a Stable School approach works within the new obligatory health advisory service is shown in Box 1 below. In practice, the way of planning each individual meeting and communicating during a Stable School session is very similar to the model described above. In December every year, all Stable School groups are formally closed, and farmers can sign up if they want to participate in a Stable School in the following year, or in one of the other options. This is organised to ensure a continuous dynamic of the process at each farm, constantly challenging and viewing the herd and farm situation with 'fresh eyes'. The organisation Organic Denmark and The Danish Cattle Health Advisory Centre collaborate to ensure a systematic process in which special requests (e.g. participation in a 'Jersey group' or a 'milking robot group' for a year), and logistics (mostly distance between farms) can be taken into consideration when forming the groups.

\section{Questionnaire Survey}

In October 2011, 149 farmers from the 25 Danish Stable Schools received an online questionnaire regarding their 


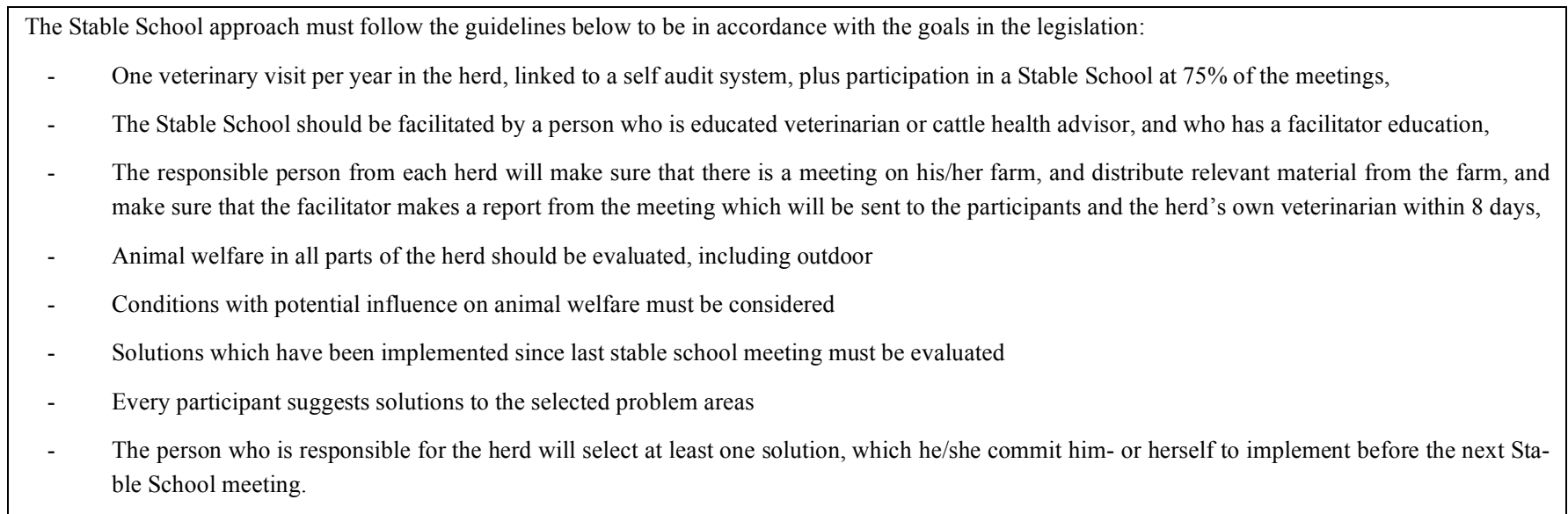

Box (1). The legislative requirements for the Stable School approach as part of the obligatory animal health advisory service, where only one meeting per farm is required. In the original model, there were two meetings per farm during a year. In practice, the facilitator distributes the material before the meetings. In the model developed in 2005, the host farmer should select one success case and two problem area which he/she wants to improve, for each meeting, This is also what happens in practice now, and the rule that 'animal welfare in all parts of the herd should be evaluated, including outdoor', is therefore taking place during the farm work prior to the meeting.

Table 1. Participants from the Farms, and Interaction with the farm Veterinarian Regarding the Outcomes of the Stable School Participation (Number of Respondents to each Question in Brackets after the Question)

\begin{tabular}{|c|c|c|}
\hline Question and Response Options & No. Respondents & \% Respondents \\
\hline \multicolumn{3}{|c|}{ Who participate(d) from your farm at the meeting in your farm? $(\mathrm{N}=77)$} \\
\hline - Owner & 75 & 97.4 \\
\hline - $\quad$ Herd manager & 14 & 18.2 \\
\hline - Employees & 22 & 28.4 \\
\hline - Others & 4 & 5.2 \\
\hline \multicolumn{3}{|c|}{ Who participate(d) from your farm at the meeting on other farms? $(\mathrm{N}=78)$} \\
\hline - Owner & 75 & 96.2 \\
\hline - Herd manager & 13 & 16.7 \\
\hline - $\quad$ Employees & 8 & 10.3 \\
\hline - Others & 3 & 3.8 \\
\hline \multicolumn{3}{|c|}{ Did any advisor participate in any of the meetings in your group? $(\mathrm{N}=78)$} \\
\hline - Yes, my own veterinarian & 3 & 3.8 \\
\hline - Yes, my own cattle health consultant & 7 & 9.0 \\
\hline - Yes, another farm's veterinarian & 8 & 10.3 \\
\hline - Yes, another farm's cattle health consultant & 1 & 1.3 \\
\hline - $\quad$ Others & 1 & 1.3 \\
\hline - No & 61 & 78.2 \\
\hline
\end{tabular}

experience and participation in the meetings. Many of the questions are presented in Tables $\mathbf{1 - 3}$ below.

\section{RESULTS}

In total, 79 farmers responded to the electronic questionnaire. Of them, 54 had participated in a Stable School before 2011, and 25 had attended one for the first time. When asked 'What made you choose the Stable School approach instead of the cross-disciplinary advisory service or other types of animal health advisory service?' with the option for crossing out more than one response, $78.5 \%$ responded 'Collaboration and meeting with other organic farmers', and $60.9 \%$ responded 'Possibilities to see other farms'. 46\% mentioned positive previous experience with participating in a Stable School. Only $17.9 \%$ of the farmers selected a common goal, on which they worked in the group.

\section{Who Participated in the Farmer Groups from Each Farm?}

At the time of response, $5.2 \%$ of the respondents had not yet held the meeting on their own farms. In Table 1, results from participants from the farms where the meetings were held are given. As can be noticed from this table, the owner 
Table 2. Agenda and Role Distribution in Stable School Meetings (Number of Respondents to each Question in Brackets after the Question)

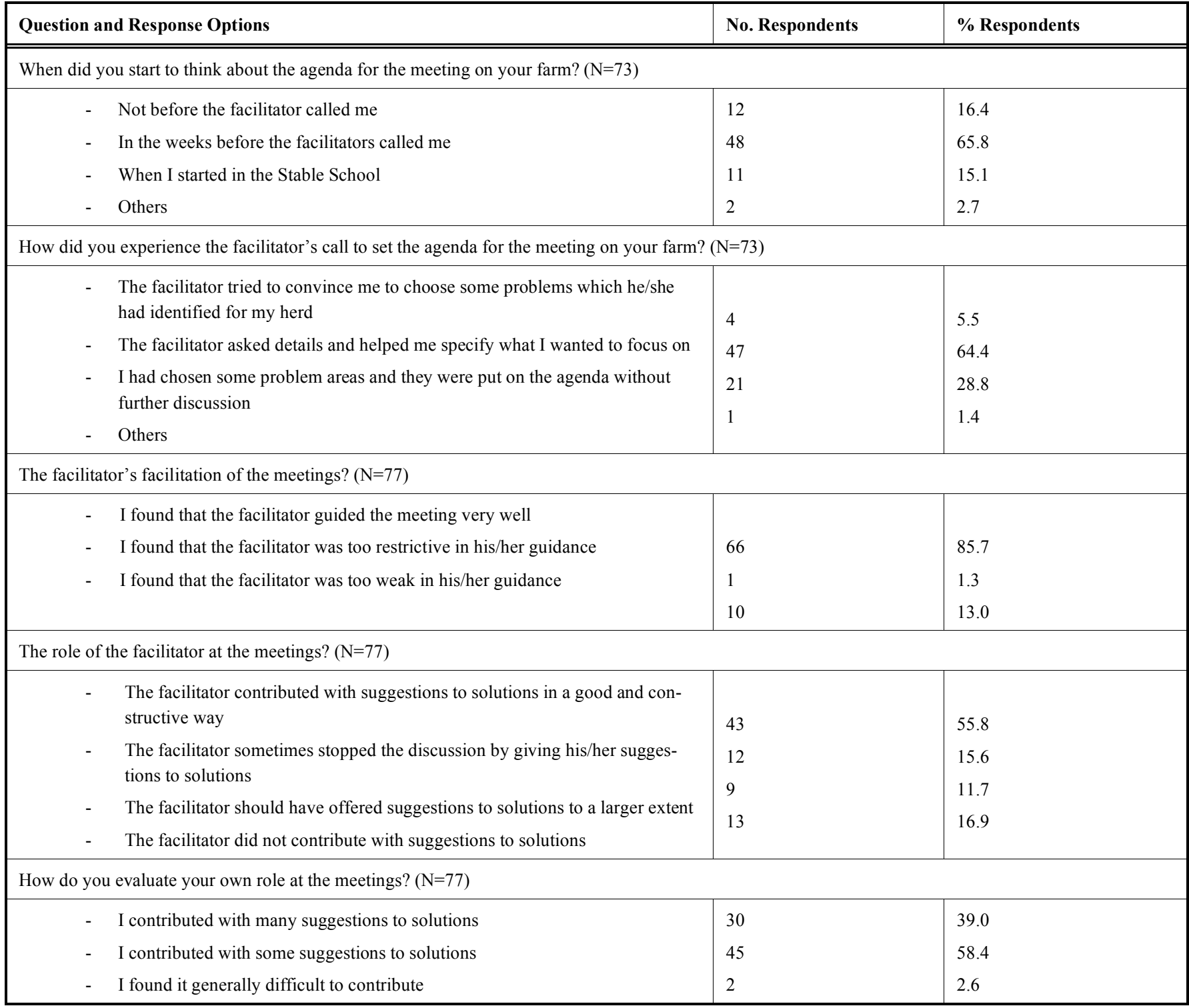

participated in the majority of the cases. There were only farmers and facilitator - and no advisors - present in $78.9 \%$ of the groups.

\section{Setting the Agenda for the Farm Meetings}

The Stable School concept is built on meetings, where the host farmer sets an agenda, helped by the facilitator, who sends this and information from the farm to all group participants. Each host farmer should select two problem areas, which he/she wants to work with. As shown in Table 2 above, a large proportion of the farmers had considered the topics for the agenda before the facilitator called, or even already at the time of joining the group.

\section{How did the Facilitator Manage their Role?}

In the original as well as in the new Stable School model, the advice was to be given by fellow farmers, not by the facilitator. However, more than half of the respondents had experienced that the facilitator had also contributed to the meetings by giving advice, on an equal level with the fellow farmers. $15.6 \%$ of the respondents said that the facilitator had stopped or inhibited the discussion when suggestions were aired, and $11.7 \%$ of the respondents wished that the facilitator had contributed with more advice.

\section{Did the Farmers Get Help to Solve their Problems?}

Each farmer should identify two problem areas, which he/she wants to commit her/himself to solve. Approximately $90 \%$ of the respondents responded that they had got help from their colleagues in solving at least one of their identified problem areas, as indicated in Table $\mathbf{3}$ below.

\section{DISCUSSION}

\section{The Method of Using an Online Questionnaire}

Results of an online questionnaire provide only superficial responses to how a farmer group approach works for the participants in their daily practice, and in-depth research 
Table 3. How did the Stable School Participation help the Farmer to Solve Problems in the Herd? (Number of Respondents to each Question in Brackets after the Question)

\begin{tabular}{|c|c|c|c|}
\hline & Question and Response Options & No. Respondents & $\%$ Respondents \\
\hline \multicolumn{4}{|c|}{ Did the Stable School group discuss your problem areas in a way which contributed significantly to solve the selected problems in your herd? (N=73) } \\
\hline & Yes, with regard to both problem areas & 33 & 45.2 \\
\hline & Yes, in particular with one selected problem area & 30 & 41.1 \\
\hline & No, not really, no good suggestions & 6 & 8.2 \\
\hline & No, they were not concrete in a way that stimulated action & 1 & 1.4 \\
\hline & Others & 3 & 4.1 \\
\hline \multicolumn{4}{|c|}{ How useful did you find the meeting notes? $(\mathrm{N}=73$ ) } \\
\hline & Fine to move on with & 36 & 49.3 \\
\hline & Ok, but did not contribute with more than the meeting itself & 31 & 42.5 \\
\hline & I did not use the notes for anything & 4 & 5.5 \\
\hline & Others & 2 & 2.7 \\
\hline \multicolumn{4}{|c|}{ Did the Stable School live up to your expectations? $(\mathrm{N}=77)$} \\
\hline & Yes & 72 & 93.5 \\
\hline r & No & 5 & 6.5 \\
\hline
\end{tabular}

interviews (either individual or in a focus group) could have been desirable. The fact that 79 out of 149 farmers responded, although not always to every question, raises another important issue: who did not respond, and why? In other words, this questionnaire survey cannot give sufficient background for claiming that 'the Stable School model works well in a legislative framework', nor for claiming the opposite. Nevertheless, it can support a discussion and fundamental questioning of the conceptual framework for using the Stable School model as a means for keeping animal health and welfare at a minimum requirement level in Danish organic dairy herds. This is the main question in the following discussion, which will be based on reflections on the legislation as well as literature discussing institutionalization of advisory services in different forms.

\section{The Sense of Ownership}

The fact that approx. $81 \%$ of respondents had thought of the agenda for their own farm at least in the weeks before the meeting, and more than $90 \%$ had set their own agenda, and also that over $90 \%$ perceived themselves as active at the meeting, gives indications of ownership, active participation and situated learning in a group. Group members are able to help the host farmer by offering suggestions which solve his/her problems in ways which are relevant to the particular farm. The unique farm context makes it different from any other participating farm, and it is important that all group members understand and respect the characteristics of this specific farm context. It is imperative to the group process that the facilitator can guide each farmer's description of the problem areas as well as the group discussion on the specific farms, so that the learning process takes place and the coconstructed knowledge is relevant to all.

\section{The role of the Facilitator}

Each meeting focuses on farmers giving a colleague farmer advice in a goal-directed way. The facilitator must keep the balance between encouraging farmer ownership and still challenging the farmer. This challenge may be emphasised in this small questionnaire survey through the fact that $10 \%$ of the respondents did not feel that they had received applicable suggestions for solutions. The combination of facilitators who had apparently accepted a farmer's suggestions for the agenda without probing, and those who had more or less decided or pushed for a certain point being taken up in the meeting, potentially indicates a necessity to better educate facilitators to aim for sharp and precise formulations of the agenda, and to ensure that each farmer has received useful advice.

\section{The Alternative to Stable Schools in the Danish Legisla- tion}

Directive 786 became applicable in organic herds from the beginning of 2011. By the beginning of the year, 308 organic farmers had 100 cows or more per year and were therefore obliged to find a way of effectuating the herd health advisory service. The legislation allows each farmer to choose the approach which they are most attracted to, unless they have been reported for non-compliance to the animal protection law. If this is the case, the herd owner is obliged to have at least 12 yearly advisory service visits by the veterinarian. According to the coordinated admission for Stable School participation, 149 organic dairy producers had chosen to participate in a Stable School, and 18 had chosen to participate in the ordinary veterinary herd health service, one of these with fewer than 100 cows. Nineteen of the Stable School participants had 50-100 dairy cows, so they participated voluntarily. 152 farmers had elected to have 2 annual meetings with a team comprising their local practising veterinarian and their cattle health advisor (a consultant, mostly with an educational background as an agricultural scientist or agricultural technical advisor). Not all farmers will be attracted to a farmer group approach, and participating in a farmer group year after year can also become repetitive. The 
Stable School approach contained the idea of closing each group after one year. This was decided on to keep the dynamics and spirit in the group high, based on experience from the so-called 'erfa-groups' (experience exchange groups), which were described by many farmers and coordinators as 'nice social groups', but with no ambitions of dynamic development or helping each farmer to push for improvements. It can be questioned whether it is possible to maintain a highly active, dynamic level in a group when farmer group participation becomes 'an everyday thing, year after year'. Shifting between different approaches can potentially contribute to a more dynamic process on each farm.

Stable Schools were farmer-driven and formed to phase out antibiotics by promoting animal health. By integrating the Stable School concept into the legislation, a move was made from a framework within which farmers had their own controversial agendas to taking ownership of their own situations in a framework, which uses farmer groups to make farmers live up to certain standards and legislation. Was the Stable School approach 'rebellious' when it was developed in 2004-2005? The initiative was farmer-driven, and the common goal of "phasing out antibiotics from the herds through active health and welfare promotion' was an alternative compared to that of other farmers in Denmark, who at that time were fighting for the right to treat with antibiotics themselves under the supervision of the veterinarians. Veterinarians were not regarded as competent or interested in assisting organic farmers in meeting this goal according to many organic farmers. This was stated in Denmark [17] as well as on European level [18]. Farmers could assist fellow farmers to find alternative methods, and they could deal with the farming complexities, which is very difficult for many specialised advisors, who are familiar only with their area of expertise. The 'revolutionary idea' in the Stable Schools, apart from the goal, was the approach itself. Farmers gave goal-directed advice to each other rather than 'just chatting in social groups', as expressed by a farmer [7 page 5; translated by first author]: 'The renewing aspect of this is that we come together here, six peasants, and actually talk on an equal level with 'the clever people". The overall goal to phase out antibiotics from the herds can be seen as a new and controversial one, breaking with common disease focus, and turning it into a health-promoting focus. Farmers went against the stream and created 'Community of Practice' groups where they went through social learning processes. In this case it happened in a structured and focused way in a short (one-year) process which turned out to bring sustainable changes in farming practices and in many cases initiate a development which continued on the farms even after the group had been closed. The Stable School farmers attracted some public attention and debate. Probably, these results and debates were paramount for pushing the Stable School idea into a legislative framework, which did not have any vision or purpose of creating a platform for collection action or 'being rebellious', in terms of working against conventional or further industrialisation of organic dairy production, or setting agendas in society for alternative food systems or similar. There seems to be a fundamental mismatch between the two purposes of Stable Schools: 1) as a farmer-driven and farmer-owned group approach, and 2) as a way of fulfilling the legislation and ensuring minimum animal welfare and health standards. The first type aims at being a highly dynamic, inspiring, change-oriented and intense one-year development process of a farm and the participating farmers. The latter is a way of ensuring minimum requirements of animal welfare and health in herds, and is partly focused on documenting this. As previously explained, all Stable Schools are formally terminated at the end of each year, and farmers can choose which advisory model they want to use next year. It is nevertheless mandatory to have an advisory service agreement, and therefore the farm process which will continue year after year. This mismatch may call for attention and lead to future adjustment of the concept of Stable Schools, so that the aim becomes clear and there will still be a possibility for create space for intense development processes.

\section{Stable Schools from 'Farmer Owned' to 'Legislation'}

The development of Stable Schools from a farmer-driven initiative to 'complying with the law by being a member' can potentially lead to a shift in the whole construction of this farmer group approach.

Farmers are motivated by different things to attend a farmer group. Farmers in a Norwegian Stable School initiative (pilot groups, 2009, and 39 facilitators educated in 2010) were very attracted to the social linking up with fellow farmers in combination with the practical problem-solving opportunities $[19,20]$. The approach was constructed to stimulate farmers to focus on responding to their own challenges, and find relevant and directly applicable solutions. The host farmer must set the agenda; all fellow farmers are experts who give advice on the basis of the agenda, and the host farmer concludes. Within the Stable School framework - no matter whether it is part of legislation or not - the farmers can find opportunities to improve their farm and to build up social capital with other farmers through networking and communication. Formalised long-term collaboration has never been part of the concept. It is crucial that the farmers take ownership and set their own agendas. All group members are mutually dependent on the active participation and commitment of everybody in the group. There is a risk that just one farmer, who participates without genuine interest but only to avoid 'other types of obligatory health advisory service', can create a passive and dead point in the group. Atkinson and Neale [21] concluded based on evaluations of the effect of the British obligatory animal health plan that most farms had the required plan, but it was not valued or reviewed. They concluded that the farmer should take responsibility for the plan, if it should be meaningful.

\section{CONCLUSIONS}

Stable Schools were generally found to be useful and relevant for many organic farmers in an online questionnaire survey with 79 (out of 149 potential) respondents, also as a part of the legislation. The success of Stable Schools is built on farmer motivation to take ownership. Farmer groups must be facilitated by a skilled facilitator, who actively supports this. The risk of involving non-motivated farmers increases when the approach is part of the legislation, especially if alternatives to Stable Schools are less attractive; for example, some farmers found that veterinarians lack skills and interest in organic dairy production. The Stable School approach in a legislation framework does not have the aim of 
stimulating farmers to collective action, choosing new goals or identifying radical new directions, but is a way in which society attempts to ensure that animal health and welfare is maintained at a minimum required level. This fundamental mismatch between the aims of Stable Schools in the former and in the legislative frameworks can potentially lead to a development of the approach towards a less dynamic and development-oriented focus. It is highly questionable that continuous group participation under these conditions can bring farmers new inputs. Shifting between different advisory approaches is a potential solution.

\section{CONFLICT OF INTERESTS}

The authors confirm that this article content has no conflicts of interest.

\section{ACKNOWLEDGEMENTS}

The farmers participating in this survey and workshop, as well as our colleagues in Organic Denmark and Danish Cattle Advisory Centre are gratefully acknowledged for their contribution to this material and discussion on various stages. Thank you to Gidi Smolders for valuable comments to this manuscript.

\section{REFERENCES}

Gallagher, K., Braun, A. Duveskog, D. Demystifying Farmer Field School Concept, 2006.

http://ecoport.org/storedReference/559780.pdf

[2] Minjauw B, Muriuki HG, Romney D. Development of Farm Field School Methodology for smallholder dairy farmers in Kenya. International Learning Workshop on Farmer Field Schools (FFS): Emerging issues and challenges, Yogyakartu, Indonesia, $21^{\text {th }}-25^{\text {th }}$ October 2002, pp. 13.

[3] Byarugaba DK, Nakavuma JL, Vaarst M, Laker C. Mastitis occurrence and constraints to mastitis control in smallholder dairy farming systems in Uganda. Livestock Res. Rural Dev. 2008; 20(1): 13 .

[4] Vaarst M, Byarugaba D, Nakavuma J, Laker C. Participatory Livestock Farmer Training for improvement of animal health in rural and peri-urban smallholder dairy herds in Jinja, Uganda. Tropical Anim Health Product 2007a; 39(1): 1-11.

[5] Rubaire-Akiiki CM, Okello-Onen J, Musunga D, et al. Effect of agro-ecological zone and grazing system on incidence of East Coast Fever in calves in Mbale and Sironko Districts of Earstern Uganda. Prevent Veterin Med 2006; 75(3-4): 251-66.
[6] Vaarst M, Nissen TB, Østergaard S, Klaas IC, Bennedsgaard TW, Christensen J. Danish stable schools for experiential common learning in groups of organic dairy farmers. J Dairy Sci 2007b; 90: 2543-54

[7] Lisborg L, Vaarst M, Nissen TB. Staldskolehåndbogen [The Stable School Handbook. In Danish]. http://orgprints.org/13773, 2005

[8] Vaarst M. Participatory Common Learning in Groups of Dairy Farmers in Uganda (FFS approach) and Danish Stable Schools, Aarhus University, Faculty of Agricultural Sciences 2007: p. 78.

[9] Bennedsgaard TW, Klaas IC, Vaarst M. Reducing Use of Antimicrobials - Experiences from an Intervention Study in Organic Dairy Herds in Denmark. Livestock Sci 2010; 131(2-3): 183-92.

[10] Nicholas P, Roderick S, Vaarst M. Animal Health and Welfare Planning - Identifying key principles and approaches. In: Vaarst, M Roderick, S (Eds.), Planning for better animal health and welfare report from the 1st Aniplan project workshop, Aarhus University, Faculty of Agricultural Sciences 2008: pp. 23-5.

[11] Kolb D. Experiential learning. Experience as the source of learning and development. Prentice hall, Englewood Cliffs, New Jersey 1984.

[12] Lave J, Wenger E. Situated learning. Legitimate peripheral participation. Cambridge University Press, UK 1991.

[13] State Bank Denmark . Detailed statistical information on the Danish society 2006. http://www.statbank.dk/statbank5a/default.asp? $\mathrm{w}=1280$

[14] Anonymous. Kvægbruget $\mathrm{i}$ tak [Cattle production in figures. In Danish]. Danish Cattle Federation 2009, http://www.landbrugsinfo.dk/Kvaeg(Tal-om-kvaeg/Sider/Kvaegbruget_i_tal_2009.aspx

[15] Anonymous. Fakta om mælkeproduktion [Facts about dairy production. In Danish]. Knowledge Centre for Farming 2011, http://www.vfl.dk/Afdelinger/Kvaeg/FaktaOmKvaegproduktion/Fa ktaOmKvaegproduktion.htm

[16] Anneberg I. Actions of and interactions between authorities and livestock farmers - in relation to animal welfare. $\mathrm{PhD}$ thesis, Science and Technology, Aarhus University 2013: p. 207.

[17] Vaarst M, Thamsborg SM, Bennedsgaard TW, et al. Organic dairy farmers' decision making in the first two years after conversion in relation to mastitis treatments. Livestock Prod Sci 2003; 80: 109 30 .

[18] Vaarst M, Padel S, Arsenos G, et al. Challenges for animal health and welfare in the implementation of the EU legislation on organic livestock production: Analysis of questionnaire survey among SAFO participants, In: Future perspectives for animal health on organic farms: main findings, conclusions and recommendations from the SAFO Network, Fischer Taschenbuch Verlag - Forum Wissenschaft Hochschule 2006: pp. 43-74.

[19] Hovland D. Samlast til Fjøsskule Gathered in Stableschool. In Norwegian. Sør- og Middalen 2011: 15.

[20] Hektoen L, og Sogstad Å.M. Gode erfaringer fra fjøsskoler for saue- og storfeprodusenter. Good experiences from Stable Schools for sheep- and cattle producers. Praksisnytt 2011; 3: 14-22.

[21] Atkinson C, Neale M. Animal Health Planning and Animal Health Plans. Concepts, Principles Pract 2008: 5. http://orgprints.org/13406/1/13406.pdf 